\title{
Asymptomatic Occipital Area Infarction following Carotid Body Paraganglioma Excision
}

\author{
${ }^{1}$ Vishal Rao, ${ }^{2}$ Sudhir M Naik, ${ }^{3}$ MK Goutham, ${ }^{4}$ Mohan Appaji, ${ }^{5}$ Shankarnarayan Bhat, ${ }^{6}$ Rudresh Hiremat \\ ${ }^{7}$ Navya Rangnath, ${ }^{8}$ Ravi Shankar S Bhat
}

\begin{abstract}
Background: Vascular complications are seen in 2 to $13 \%$ of cases with internal carotid artery (ICA) injuries with or without reconstruction. The hypoglossal and vagus appeared most vulnerable for permanent paralysis due to traction or resection. Mortality with surgical excision of carotid body tumor (CBT) has become negligible with newer vascular surgical techniques and the morbidity has fallen to minimal $2.56 \%$.
\end{abstract}

Case report: We report a case of 24 -year-old female with symptomatic CBT excision with external carotid artery (ECA) ligation. She developed asymptomatic infarction of the occipital lobe. All the cranial nerves were intact with a follow-up uneventful for the past 2 years.

Conclusion: Minimizing complications in CBT surgery include an accurate preoperative imaging assessment of the tumor with comorbidities and evidence-based management.

Keywords: Paraganglioma, Shamblin classification, Magnetic resonance angiography, Cerebrovascular accident.

How to cite this article: Rao V, Naik SM, Goutham MK, Appaji M, Bhat S, Hiremat R, Rangnath N, Bhat RSS. Asymptomatic Occipital Area Infarction following Carotid Body Paraganglioma Excision. Int J Head Neck Surg 2014;5(3):148-151.

Source of support: Nil

Conflict of interest: None

\footnotetext{
${ }^{1}$ Senior Consultant, ${ }^{2}$ Fellow, ${ }^{3,6,7}$ Assistant Professor

${ }^{4}$ Professor, ${ }^{5,8}$ Associate Professor

1 Department of Head and Neck Oncosurgery, Global Hospitals Bengaluru, Karnataka, India

${ }^{2}$ Department of Cosmetic and Image Enhancement Surgery Cosmetic Surgery Institute, Mumbai, Maharashtra, India

${ }^{3,4}$ Department of ENT, Head and Neck Surgery, KVG Medical College, Sullia, Karnataka, India

${ }^{5}$ Department of Anesthesia, KVG Medical College, Sullia Karnataka, India

${ }^{6}$ Department of Radiodiagnosis, KVG Medical College, Sullia Karnataka, India

${ }^{7}$ Department of Pathology, KVG Medical College, Sullia Karnataka, India

${ }^{8}$ Department of ENT, KVG Medical College, Sullia, Karnataka India
}

Corresponding Author: Ravi Shankar S Bhat, Associate Professor, Department of ENT, KVG Medical College Sullia, Karnataka, India, Phone: 9916807109, e-mail: drraveesha@gmail.com

\section{INTRODUCTION}

Mortality with surgical excision of carotid body tumors (CBTs) has become negligible with newer vascular surgical techniques and the morbidity has fallen to minimal $2.56 \% .{ }^{1}$ The neural damage in larger tumors may be around 10 to $44 \%$ but is lesser considering the complex operative anatomy and adhesion to these neural elements. ${ }^{1}$ Permanent neural damages are lesser $(12 \%)$ and considering the invasive nature of the tumor, the tumor should be excised at the time of diagnosis. Internal carotid artery (ICA) shunting plays a major role in maintaining cerebral circulation and shrink the tumor by excluding the external carotid artery (ECA) thus creating the cleavage planes where dissection becomes difficult. ${ }^{2}$ Shunt insertion, when used with appropriate anticoagulation, reduces severe cerebrovascular complications. ${ }^{2}$

Vascular complications are seen in 2 to $13 \%$ of cases with ICA injuries with or without reconstruction.,4 The hypoglossal and vagus appeared most vulnerable for permanent paralysis due to traction or resection. ${ }^{3,4} \mathrm{We}$ report a case of asymptomatic occipital area infarction following CBT resection in Shamblin IIIa tumor with ECA ligation and no damage or reconstruction of the ICA.

\section{CASE REPORT}

We report a case of 24-year-old female with symptomatic carotid body paraganglioma operated at our institute. A small pulsatile palpable mass in the left lateral neck at the level of the hyoid was investigated. It appeared as a hyperechoic mass at the carotid bifurcation. Contrast enhanced computed tomography (CECT) reported an enhancing lesion at the carotid bifurcation with a provisional diagnosis as carotid body paraganglioma (Fig. 1).

Magnetic resonance contrast angiogram confirmed it as Shamblin IIIa carotid body paraganglioma. No luminal infiltration was seen on axial sections in ICA. The upper, lower extent of the tumor, the volume of the tumor, level of encircling of the ICA and common carotid artery (CCA), the continuity of the circle of Willis was all noted. No embolization was done. The case was operated under general anesthesia under anticoagulation. A curvilinear transverse incision was taken and the flap elevated, exposing the carotid sheath, and the tumor defined. The hypoglossal nerve was retracted up and the vagus was dissected well away laterally (Fig. 2). 
A craniocaudal dissection was done, the tumor encircling the ECA was dissected, and the feeders were cauterized. Complete cleavage dissection of the ECA was not possible as the lumen was involved, so the ligation was done flush to the bifurcation. The dissection was near to the tumor and so the superior laryngeal nerve was uninjured. Later the bifurcation was exposed and the tumor reflected to the ICA and dissected off along the 'white line'. No shunting was done, and no injury to the ICA seen. The histopathology of paraganglioma was seen and immunohistochemistry where all the tumor cells were positive for synaptophysin and chromogranin, negative for cytokeratin. The sustentacular cells were positive S-100.

The recovery was uneventful with no neurological damage. The patient was discharged after 3 days and was followed-up, she complained of giddiness on the fourth day but otherwise normal. A CT scan of brain was done, and an infarct was seen in the occipital area. The vision was normal, with retinoscopy and fundoscopy normal. All other cranial nerves were normal. The patient was asymptomatic later and is followed-up for the past 4 years.

\section{DISCUSSION}

Carotid body tumors were classified based on their size as grade I: easily dissected away from the vessel wall, grade II: intimately associated and compressed carotid vessels, but could be separated with careful subadventitial dissection, grade III: large and typically encased the carotid artery requiring partial or complete vessel resection and replacement. ${ }^{5}$ Grade III had higher risks of vascular injuries, but this classification did not elaborate the risks of nerve injuries and smaller tumors having ICA luminal infiltration. ${ }^{6}$ Luna-Ortiz et al classified grade III into: (a) $>4 \mathrm{~cm}$, tightly adherent to ICA and cleavage found with difficulty, (b) any size with intramural infiltration seen and vessel sacrifice and reconstruction imminent. ${ }^{6}$

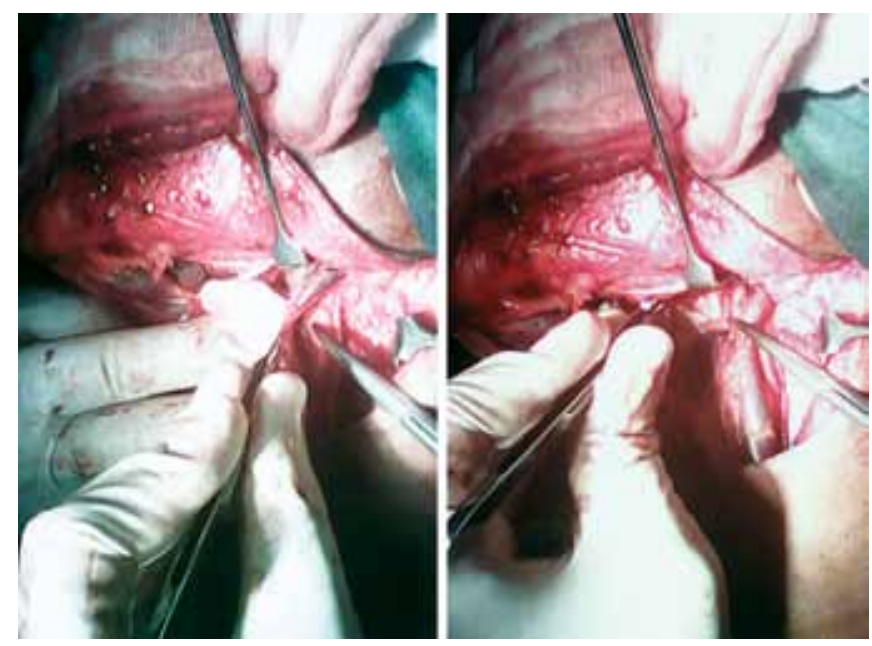

Fig. 1: ECA being clamped during dissection of the tumor
Recently, a working classification based on the modified Shamblin grading and multislicer CT and MR angiogram was put forth; group I: tumor encircling up to $180^{\circ}$ of ICA $(<4 \mathrm{~cm})$, group II: tumor encircling 180 to $270^{\circ}$ of ICA $(<4 \mathrm{~cm})$, group IIIa: tumor encircling more than $270^{\circ}$ of ICA $(>4 \mathrm{~cm})$, group IIIb (type I): partial infiltration of ICA and encircling up to $180^{\circ}(<4 \mathrm{~cm})$, group IIIb (type II): partial infiltration of ICA and encircling 180 to $270^{\circ}(<4 \mathrm{~cm})$, group IIIb (type III): partial infiltration of ICA and encircling more than $270^{\circ}(>4 \mathrm{~cm})$. Also, the circumferential contact with the ECA and CCA, the free segment of ICA are important for vascular reconstruction of carotid if resection done. ${ }^{7}$

A craniocaudal dissection with all neurovascular structures separated off the tumor without damage reduces complication of neurovascular injury. ${ }^{8}$ Proximal and distal control of the carotid arteries with early ligation of feeding arteries releases the tumor of ECA and later the ICA can be dissected off the tumor. ${ }^{9,10}$ Elective ECA ligation is not essential all times but helps tumor mobilization in larger tumors. ${ }^{9,10}$

Internal carotid artery resections should be immediately reconstructed with complete control. ${ }^{8}$ Smaller tears can be repaired by primary closure and small perforations can be controlled by patch angioplasty. ${ }^{8}$ Smaller length ICA resections can be reconstructed with ECA transposition interposition grafts, larger length ICA with autologous grafts, such as saphenous vein and femoral artery or vein, cryo-preserved arterial homograft, prosthetic graft using polytetrafluoroethylene (PTFE) or Dacron. ${ }^{8}$ During ICA clamping, carotid shunting can reduce the risk of stroke. ${ }^{8}$

According to Hallett, zone III is considered as the dangerous as all the important lower cranial nerves cross the ICA, where dissection becomes difficult and reconstruction needs expertise. ${ }^{11}$ Clamping of the proximal CCA and ICA distal to the tumor is aided by shunts which has

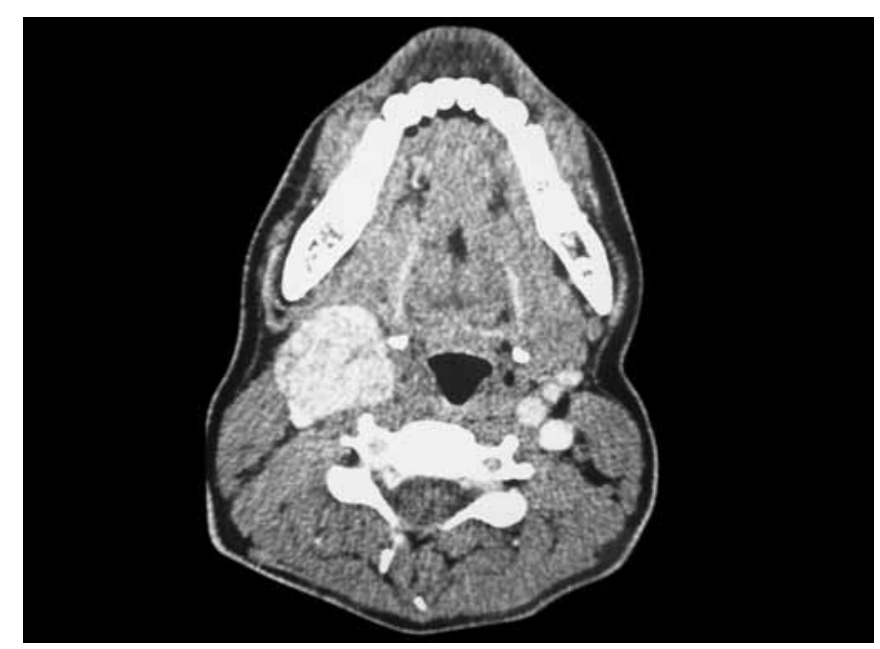

Fig. 2: Contrast enhanced CT showing the tumor 
made cerebral ischemia very minimal. ${ }^{11}$ So, the brain needs intense monitoring during clamping and shunting to reduce cerebral ischemia. ${ }^{11}$

Cerebral blood flow (CBF) monitoring is done by electroencephalogram (EEG), somatosensory evoked potential (SSEP), measurement of distal carotid stump pressure, transcranial Doppler blood flow measurements and cerebral oximetry. ${ }^{12,13}$ Pressure in CCA distal to clamp reflects the pressure in the ICA and is proportional to the manipulations of systemic blood pressure. ${ }^{13}$ Common techniques to reduce cerebral ischemia include elevation of cerebral blood pressure at time of clamping to promote collateral flow to the ischemic hemisphere. ${ }^{13}$ This reverts back the ischemic changes in EEG and averts ischemic injury. ${ }^{13}$

Blood loss which may have a prolonged and excessive decreases in blood pressure may jeopardize the cerebral perfusion pressure (CPP) and the adequacy of CBF through collateral channels. ${ }^{14}$ Hypothermia has a protective effect but cannot take off instantly at the time of clamping. ${ }^{14}$ Titrated dose of barbiturates reduces cerebral metabolic rate of oxygen $\left(\mathrm{CMRO}_{2}\right)$, free radical scavenging, inhibition of calcium uptake and protection from nitric oxide induced cytotoxity. ${ }^{15}$ Also, barbiturates reduce intracranial pressure (ICP) and redistribute $\mathrm{CBF}$ from perfused to ischemic areas (inverse steal), so optimal dosing time is to be titrated and monitored well. ${ }^{16}$ Thiopentone bolus suppresses $\mathrm{CMRO}_{2}$ for 5 to 10 minutes causes hypotension and should be managed with titrated volume expanders and vasopressors. ${ }^{17}$

Hyperglycemia exacerbates ischemic cerebral damage, so dextrose-free fluid is recommended if the carotid artery is clamped and heparin reduces intravascular thrombosis in areas of stasis. ${ }^{18}$ Baroreflex failure is rarely seen if bilateral CBT are excised and postoperative stroke and myocardial infarction can occur. ${ }^{19}$ CBT probably functions as a giant peripheral chemoreceptor, which may suppress the chemoreceptor function of the contralateral carotid body, so after excision instances of severe postoperative respiratory depression are also reported..$^{20}$ Opoid analgesics may be additive, so lowest possible is used. ${ }^{21}$

Cranial nerve damage can be seen with 9, 10 and 12, cervical sympathetic nerves and marginal mandibular branch of 7 th nerve. ${ }^{22}$ They may be damaged iatrogenic damage, tissue edema causing nerve palsy postoperatively and rarely by tumor invasion preoperatively. ${ }^{22}$ Airway compromise either by aspiration or obstruction can be seen with 9th, 10th, 12th cranial nerve dysfunction. ${ }^{22}$ Invasive blood pressure monitoring with arterial line, CVP monitoring and continuous urinary catheterization with fluid management are essential. ${ }^{19}$ CBT dissection caused reflex bradycardia can be managed by intravenous atropine or by topical application of local anesthetic lidocaine around the carotid sinus. ${ }^{19}$

\section{CONCLUSION}

Minimizing complications in CBT surgery include an accurate preoperative imaging assessment of the tumor with comorbidities, a meticulous craniocaudal operative technique, shunt placement whenever required, appropriate anticerebral ischemia measures and protocol-based postoperative management.

\section{REFERENCES}

1. Grotemeyer D, Loghmanieh SM, Pourhassan S, Sagban TA, Iskandar F, Reinecke P, Sandonann W. Dignity of carotid body tumors: review of the literature and clinical experiences. Chirurg 2009 Sep;80(9):854-863.

2. Zeng G, Zhao J, Ma Y, Huang B. Use of an intraoperative shunt for easy resection of complicated carotid body tumors. Head Neck 2013 Jan;35(1):61-64.

3. Makeieff M, Raingeard I, Alric P, Bonafe A, Guerrier B, MartyAne C. Surgical management of carotid body tumors. Ann Surg Oncol 2008 Aug;15(8):2180-2186.

4. Luna-Ortiz K, Rascon-Ortiz M, Villavicencio-Valencia V, Herrera-Gomez A. Does Shamblin's classification predict postoperative morbidity in carotid body tumors? A proposal to modify Shamblin's classification. Eur Arch Otorhinolaryngol 2006 Feb;263(2):171-175.

5. Lotina S, Davidoviæ L, Havelka M, Vojnoviæ B, Neškoviæ V, Stojanov P, Kecman N. Carotid body tumors. J Serbian Med Soc 1997;125(3):278-284.

6. Luna-Ortiz K, Rascon-Ortiz M, Villavicencio-Valencia V. Carotid body tumors: review of a 20-year experience. Oral Oncol 2005;41(2):56-61.

7. Arya S, Rao V, Juvekar S, Dcruz AK. Carotid body tumors: objective criteria to predict the Shamblin group on MR imaging. Am J Neuroradiol 2008 Aug;29(1):1349-1354.

8. Lim JY, Kim J, Kim SH, Lee S, Lim YC, Kim JW, Choi EC. Surgical treatment of carotid body paragangliomas: outcomes and complications according to the Shamblin classification. Clin Experimental Otorhinol 2010 June; 3(2):91-95.

9. Persky MS, Setton A, Niimi Y, Hartman J, Frank D, Berenstein A. Combined endovascular and surgical treatment of head and neck paragangliomas: a team approach. Head Neck 2002 May;24(5):423-431.

10. Wang SJ, Wang MB, Barauskas TM, Calcaterra TC. Surgical management of carotid body tumors. Otolaryngol Head Neck Surg 2000 Sep;123(3):202-206.

11. Hallett JW, et al. Trends in neurovascular complications of surgical management for carotid body and cervical management paragangliomas: a 50-year experience with 153 tumors. J Vascular Surg 1988;7(1):284-291.

12. Mac Giiivray DC, Perry MO, Sufe RW, Nydick I. Carotid body tumor: atypical angiogram of a functional tumor. J Vasc Surg 1987;14(5):462-468.

13. Spetzler RT, Martin N, Halidey MN, et al. Microsurgical endarterectomy under barbiturate protection: a prospective study. J Neurosurg 1986;65(3):63-73. 
14. Tamai H, Kuribayashi T, Sawamura S, et al. Perioperative treatment for carotid endarterectomy with induced mild hypothermia: a case report. Masui 2002;31(2):1132-1136.

15. Shibuta S, Kosaka J, Mashima T, et al. Nitric oxide induced cytotoxicity attenuation by thiopentone sodium but not pentobarbitone sodium in first degree brain cultures. Br J Pharmacol 1998;124(2):804-810.

16. Newman MF, Croughwell ND, White ND, et al. Pharmacologic electroencephalographic suppression during cardiopulmonary bypass: a comparison of thiopental and isoflurane. Anaesth Analg 1998;86(2):246-251.

17. McConkey, Kien ND. Cerebral protection with thiopentone during combined carotid endartectomy and clipping of intracranial aneurysm. Anaesth Intensive Care 2002;30(2): 219-222.
18. Clark NJ, Stanley TH. Anaesthesia for vascular surgery. In: Miller RD, editor. Anaesthesia, 4th ed. New York: Churchill Livingstone; 1994;4. p. 1851-1895.

19. Maturo S, Brennan J. Baroreflex failure: a rare complication of carotid paraganglioma surgery. Laryngoscope 2006;116(5): 829-830.

20. LeeJK,HanowellS,Kem YD,Macnamara TE. Morphineinduced depression following bilateral endarterectomy. Anaesth Analg 1981;60(3):64-65.

21. Baraka A. Postoperative respiratory depression following excision of carotid body tumors. Can J Anaesth 1994;4(1): 306-309.

22. Dardik A, Eisele DW, Williams GM, Perler BA. A contemporary assessment of carotid body tumor surgery. Vasc Endovascular Surg 2002 Jul-Aug;36(4):277-283. 